\title{
Research on the Applications of Flip Mode Technology in High Bridge Pier Construction Project and Quality Control
}

\author{
Feng Wang ${ }^{1}$ \\ ${ }^{1}$ The Engineering\&Technical College of \\ Chengdu University of Technology, \\ 614000 China \\ Xiao Lai ${ }^{1}$ \\ ${ }^{1}$ The Engineering\&Technical College of \\ Chengdu University of Technology, \\ 614000 China \\ Zhen Wen ${ }^{2}$ \\ ${ }^{2}$ Chongqing Real Estate College, \\ Chongqing, China
}

\begin{abstract}
In this paper, we conduct research on the applications of flip mode technology in high bridge pier construction project and quality control. Double mode refers to the construction of the piers of the bridge with three template mutual disassembly, constantly improve pier height, use the crane cut large pieces of the template in the process to turn up, continuously casting continuously rise, turned up through such makes the circulation homework way rising piers. Our proposed approach performs well through the numerical simulation which will be meaningful and effective.
\end{abstract}

Keywords: Flip Mode Technology; High Bridge Pier Construction; Quality Control.

\section{Introduction}

With the sustained and rapid development of economy in our country, traffic is in the constant improvement. The increase of urban construction projects as well as the rapid development of transportation industry, for the bearing capacity of highway bridges is a severe test. The continuous development of construction industry also drives the construction of the bridge engineering, bridge number more and more, all kinds of construction technology and method also emerge in endlessly. In order to ensure the overall quality of the bridge engineering, must to manage and control of the main link, high bridge pier is the main load bearing part of the bridge engineering, has direct influence on the overall quality of the bridge, its technical content is higher, the construction difficulty is relatively large, must be fully appreciated. Construction projects in roads, deep water and offshore engineering project, the engineering scale highway tunnels. In order to ensure horizontal alignment, longitudinal slope design indicators meet the requirements of high grade highway, many projects and the number of high bridge pier design increased the high pier. Higher bridge pier is increased the difficulty of construction, the construction technology put forward higher requirements.

High piers over mold technology got a widely used in the bridge construction to the advancement of techniques used to bridge pier height. Double mode refers to the construction of the piers of the bridge with three template mutual disassembly, constantly improve pier height, use the crane cut large pieces of the template in the process to turn up, continuously casting continuously rise, turned up through such makes the circulation homework way rising piers. Template with high piers, continuously elevated the pier reduced the difficulty of construction which will increase the safety and stability of the construction. So master turn technology for the construction of high piers of the bridge is very useful, continuously improves the technology, 
innovation and development is conducive to the development of technology. The pier cross-section solid slab construction strategy could be summarized as the follows. (1) To control in the construction of pier shafts of vertical degree and we are to control the verticality of the piers is mainly from three aspects. The first point: the lead weight or total station to control all the way, to timely in the process of the measurement. The second point: you can use the jack to adjust roughness of bridge piers template. The third point: concrete pouring in building a template when using the hammer, the measurement of the vertical, and directs the work of the whole bridge piers casting. (2) The weather should be considered during bridge construction, and other climate factors and the actual environmental factors. Construction should be banned in the wind, to wear safety tools in the construction. Followed by fencing on working platform, to establish close working platform, the entire construction process increase the GPS measurement, the horizontal position control and piers. (3) Piers of mold technology are regarded as a high altitude and therefore pay attention to the construction workers safety is very important. First in the licensing issues to strictly control of the workers, and to correct the use of helmets, seat belts, safety nets and other tools to improve work safety. Again is high in aerial work to prevent abortion and high fall, for the two to take measures to control respectively. In the figure one, we show the sample structure.

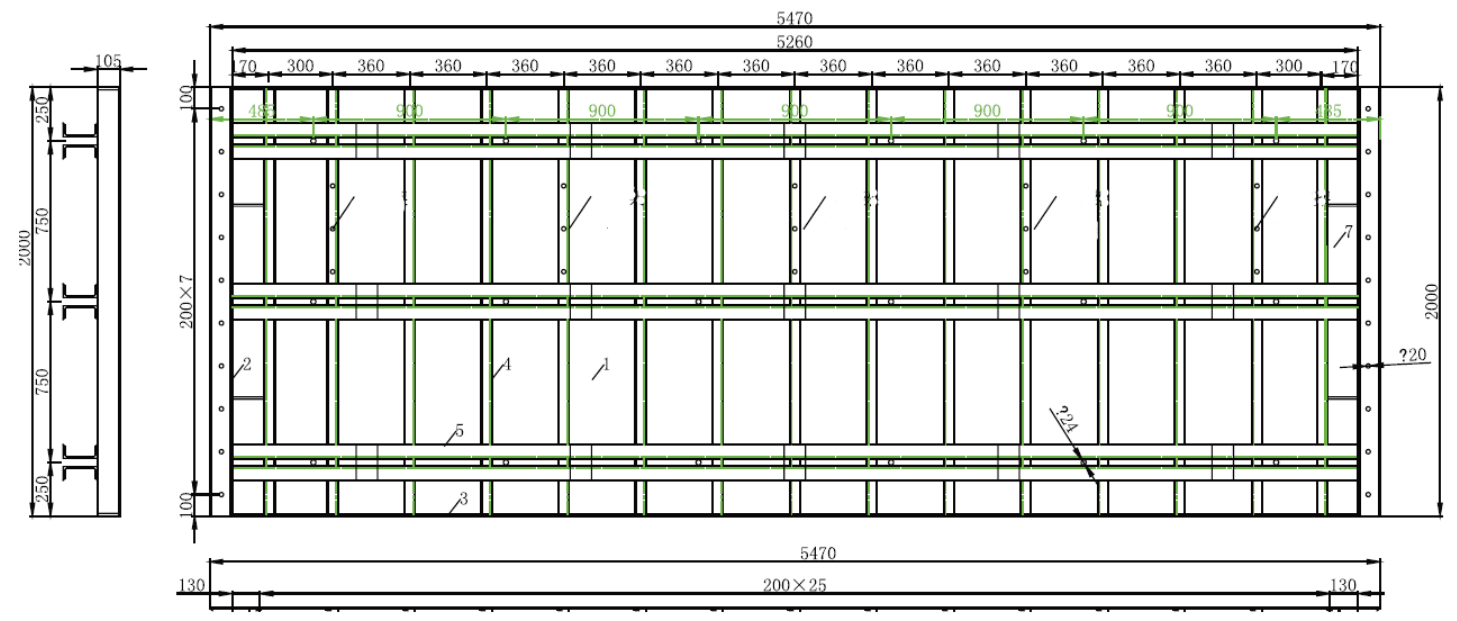

Figure 1.The Sample Structure for Analysis in the Research

In this paper, we conduct research on the applications of flip mode technology in high bridge pier construction project and quality control. Mold technology, it is to point to in the process of bridge construction, using existing has a certain strength of reinforced concrete structure, used as a model and main bearing structure, the working platform to promote and extend. After the platform to reach a certain height, can be to remove the bottom of the template, removed the template can be shipped to the top on the template for installation and calibration, and then using reinforced binding fixed, the perfusion for reinforcement and concrete which will be illustrated in the following sections.

\section{The Proposed Methodology}

The Principles of Flip Mode Technology. Rolling over construction evolved from the traditional sliding mode, through the engineering practice of recent years, gradually formed a rolling over the construction technology of today, rolling over construction is mainly composed of vertical lifting equipment, templates, and the support of three parts, including the external mold adopts refined shafts of chunks of shaped 
steel, internal model using steel or wood pattern, by high strength pull rod connected to the outer mold which is based on has been pouring concrete, dismantle the next layer seam section and section, through the vertical lifting equipment, the standard section on the top of the first layer seam section, seam section in standard, installed inside the screw and bracket, to complete the installation of the second template and pouring concrete, so a bottom-up, in turn, alternating rise, until the cycle is up to design construction height, complete the pier construction [1-3].

Rolling over technology applied in the bridge itself high bridge pier construction process could be summarized as the follows. (1) Structure of the building. Rolling over construction platform is mainly composed of a large rectangular work platform, catheters, plunger and plunger, support, and hydraulic power system, the template system and suspension system, etc., and want to purchase and installation of construction equipment, which is the best platform for the construction structure. (2) The work platform. Work platform is mainly composed of 16 double channel steel, used in the longitudinal beam and measure through bolted constitute a large working platform. Platform using climb mainly using catheter and jack fixed on the longitudinal beam which will climb device installed on the platform, etc. Around the platform above laid wood, safety nets and ensure the safety of construction personnel, and then push rod supporting platform is the main purpose of piers, the enhancement of rigid and flexible piers torsion resistance and wind resistance. In the platform, construction personnel according to the different construction link control hydraulic equipment, the last is the construction of some basic equipment, these are the basis for the rest of the work platform needed equipment and structures. (3) The composition of the hydraulic power system. The hydraulic power system is mainly composed of hydraulic pressure and high pressure pipeline, its main role is to provide platform promotion, leveling and struggle. According to jack's model, to use quota lifting force, the control of the hydraulic device, realize the change of the rising and fall the construction process. (4) Hanger installation. The installation of the hanger and use is the important part of the whole work, construction must use hanger, its main function is to provide important platform of material resources. According to different construction materials, construction link need transported into the construction of the working face directly to the material from the site, along with the ascension of the platform. (5) Construction equipment installation and buy. On the hanger installation and construction stage, the staff must be installation steps to install and implement correctly, and to repair and upgrade infrastructure in time, ensure the quality of the infrastructure. So as to ensure the safety of the use, at the same time, as well as the template system, this is a very important part of construction, according to different template type uses the different construction ways and methods, and to ensure the construction quality and efficiency, to ensure the service life of the bridge project.

The Applications of the Technology. Before construction to templates and debugging in the first place, we have to be assembled on the ground, to check the size of the templates, template roughness as well as the joint close degree, actually the template installation can be part of the error, if they are within the error range, can take the next step of the slag project, after completion of the rust removing slag should be coated with release agent, after can be stacked, save the construction site. High pier double mold technology is a high pier synovial membrane technology development, compared with a high pier synovial membrane technology has its own advantages. High pier mold technology without continuous operation, so the high pier can turn technology in construction of multiple block to operate at the same time, since it can not only improve the use efficiency of engineering 
equipment, but also saves time, shorten the construction period. Second high piers over mold technology has solved the synovial membrane technology in the construction of the status of the concrete appearance quality is unqualified, high piers over mold technology can make smooth surface smooth used in bridge construction, increased the appearance of the concrete. High piers at the same time can also turn technology and lifting equipment and concrete mixing transportation equipment good cooperate, make the whole construction process in order to speed up the construction.

Double mold technology is the use of casting has been finished and reaches a certain strength of the concrete pier, attach the template in the casting has been finished and part as its lower reaches a certain strength concrete piers, the upper erection construction template and platform. In the high pier construction process, the steel bar positioning, template installation and location as well as the concrete pouring in platform, completion of construction activities, the tower crane is used to realize the ascension of the template of the lateral platform. Closed by leveling elevation difference and according to the specific situation of the construction engineering, encryption points to meet the requirements of the elevation difference closed and go through reiteration of the corresponding level of inspection. Plane control network is the use of the owner and design institute to provide control network, according to the topography, the foundation conditions, by using the method of indirect adjustment, network encryption to the most reasonable position, as construction survey control points. Also reinforced location of embedded shafts of the timely detection, security shafts of embedded bar location accurate, not accurate time to make adjustments in a timely manner. Template by leading chain hanging on the rack body, and the guide through the pulley and roller chain on the rack body suspension beam can be slide inward or outward. Shuttering, surface sliding block to be pouring concrete, make the template near the pouring concrete surface, installation of upper and lower horizontal adjustment screw, under the command of full-time staff, fine adjustment for template; Open mode, adjust the horizontal screw, pull out the template, demolition of transverse adjusting screw, guide chain block to run away from the concrete surface, pull open the template a certain distance away from the concrete surface, for template cleaning and maintenance work by adjusting the guide chain suspension height also can adjust template elevation.

The Quality Control Approaches. Using double technology highway construction of high bridge pier, the construction unit should pay special attention to the construction quality control. Concrete process, only when the top and bottom of the concrete strength after reaching a certain degree, it on the template of concrete support, in front of the pier construction, must first processing good steel template, lacing, each section template and use bolt connect each template. Make a flip of the template must be strictly in accordance with the operation of the construction drawings, to ensure that its stiffness and strength in accordance with regulations. In the process of construction, to ensure that the shafts of the vertical precision conform to the requirements of the specification, to prevent the occurrence of eccentric top face bridge piers. Before using the template, make a template for test, and the joint of the template for processing, make sure the template does not appear the phenomenon of leakage of cement slurry. Concrete pouring process will strengthen the attention in the following three aspects: one is the concrete pump when used in concrete and premise condition is not the depth of the casting too deep. The second is for those who are buried in concrete components, construction personnel to determine the position of the embedded parts, parts after the buried and the concrete compaction which don't move the embedment parts as much as possible. Three is that, after the completion of the highway construction of high 
bridge pier concrete construction technical personnel should strengthen to need maintenance engineering, highway high bridge pier generally adopt two kinds of curing method, is a kind of high bridge pier with health cloth wrapped curing method.

Construction quality of raw materials for the high bridge pier construction quality has great influence, therefore, the construction unit to strengthen construction quality control of raw materials. Construction of raw materials before entering the construction site, the construction unit to arrange special inspectors to check the quality of construction materials, inspectors to check the quality of raw materials, factory certification certificate and other related information, as well as construction materials for sampling inspection, if it is found that the construction of raw materials have quality problem, will send back these materials, make sure you use the construction materials comply with the design requirements and specification requirements after entering the site construction materials, construction units must carry on the classification are centralized.

\section{Conclusion}

In this paper, we conduct research on the applications of flip mode technology in high bridge pier construction project and quality control. With the improvement of science and technology progress, more and more strict with the quality of highway construction, especially for the bridge, as the main and key part of the highway, its platform is one of the biggest construction difficulty, at the same time has a high technical content, safe hidden trouble in the process of its construction and all kinds of safety accident happened extremely easily, so the construction of high bridge pier has a very strict requirements. Our proposed methodology solves the corresponding issues well.

\section{Acknowledgement}

This research is financially supported by the Leshan technology bureau project (No. 14GZD146). The project name is: Bridge health monitoring and safety monitoring based on BIM technology research.

\section{References}

[1] Huang, Z. C., Jian, W. U., \& Ding, Y. J. (2006). Cast-in-situ construction of high-rise pier body for IV contract section of hangzhou gulf crossing project. Hghway.

[2] Chen, J., \& Ning, K. (2013). High pier bridge construction technology of large tonnage of rhombic hanging basket. Friend of Science Amateurs.

[3] Jian-Cou, R. (2008). Application of turnover formwork technology in gaoban bridge's high pier construction. Journal of Xiamen University of Technology. 